\title{
RECONHECIMENTO E MAPEAMENTO SÍSMICO DE PALEOCANAIS AO LARGO DA PLATAFORMA CONTINENTAL INTERNA DA ILHA DE SANTA CATARINA
}

\author{
Marina Ghedin Jerônimo ${ }^{1}$ \\ José Gustavo Natorf de Abreu²
}

Resumo: As características do fundo e da sub-superfície rasa da plataforma continental interna adjacente à ilha de Santa Catarina foi mapeada a partir da interpretação de 27 perfis sísmicos os quais evidenciaram 8 estruturas sedimentares correlacionadas a antigos sistemas fluviais, logo, considerados como paleocanais. Os refletores acústicos identificados, que representam contatos entre estratos sedimentares, denominados de R1, R2 e R3, delimitam antigos cenários deposicionais e representam sistemas pretéritos de drenagem. Os paleocanais identificados mostraram-se fortemente associados às flutuações do nível do mar desde a fase transgressiva que teve início após o Último Máximo Glacial através do afogamento de desembocaduras fluviais e da planície costeira pretérita, até o posterior recobrimento por um lençol de areias transgressivas que conformou a atual plataforma continental adjacente à ilha de Santa Catarina.

Palavras-chave: Paleocanais. Levantamento Sísmico. Plataforma Continental Interna da ilha de Santa Catarina.

\section{RECOGNITION AND SEISMIC MAPPING OF PALEOCHANNELS THROUGH THE INNER CONTINENTAL SHELF OF THE ISLAND OF SANTA CATARINA}

\begin{abstract}
The characteristics of bottom and shallow subsurface of the adjacent internal continental shelf of Santa Catarina island were mapped through the interpretation of 27 seismic profiles. Those seismic profiles demonstrated eight sedimentary structures correlated to ancient fluvial systems, thus considered as paleochannels. The identified acoustic reflectors, which represent contacts between sedimentary strata, named R1, R2 and R3, bounded old depositional scenarios and represent, past drainage systems. The identified paleochannels were strongly associated with sea level fluctuations from the transgressive phase, which began after the Last Glacial Maximum with the river mouths and coastal plain drowning, until the subsequent cover of those structures by transgressive sands conforming the current adjacent continental shelf of the island of Santa Catarina.
\end{abstract}

Keywords: Paleochannels. Seismic Survey. Internal Continental Shelf of the Santa Catarina Island.

\section{RECONOCIMIENTO Y MAPEO SÍSMICO DE PALEOCANALES A LO LARGO DE LA PLATAFORMA CONTINENTAL INTERNA DE LA ISLA DE SANTA CATARINA}

Resumen: Las características del subsuelo superficial y superficial de la plataforma continental interna adyacente a la isla de Santa Catarina se mapearon a partir de la interpretación de 27 perfiles sísmicos que evidenciaron 8 estructuras sedimentarias correlacionadas con los antiguos sistemas fluviales, por lo tanto considerados como paleocanales. Los reflectores acústicos identificados, que representan contactos

\footnotetext{
${ }^{1}$ Universidade do Vale do Itajaí, Escola do Mar, Ciência e Tecnologia, Itajaí, Brasil, mghedinjeronimo@gmail.com

2 Universidade do Vale do Itajaí, Escola do Mar, Ciência e Tecnologia, Itajaí, Brasil, gabreu@univali.br https://orcid.org/0000-0002-1090-4308
} 
entre estratos sedimentarios, denominaron R1, R2 y R3, delimitam escenarios de deposición antiguos y representan sistemas de drenaje pasados. Los paleocanales identificados se asociaron fuertemente con las fluctuaciones del nivel del mar desde la fase transgresora que comenzó después del Último Máximo Glacial a través del ahogamiento de las desembocaduras de los ríos y la llanura costera pasada hasta la posterior cobertura por una arena transgresora que se conformó la plataforma continental actual adyacente a la isla de Santa Catarina.

Palabras clave: Paleocanales. Levantamiento Sísmico. Plataforma Continental Interna de la Isla de Santa Catarina.

\section{Introdução}

A sedimentação das plataformas continentais internas carrega registros que potencialmente revelam o entendimento e as relações entre antigas feições topográficas, sobre a dinâmica litorânea, das alterações do nível médio dos oceanos (eustasia) e a morfodinâmica das linhas de costa (ROY et al., 1994; PETERSON et al., 2016; LEE et al., 2017 apud COOPER et al., 2018).

$\mathrm{Na}$ investigação dos processos de formação e sedimentação de fundo e subfundo marinho e das flutuações eustáticas têm sido amplamente empregados métodos sísmicos de alta resolução para aquisição e análise de dados (SUMIDA et al., 2004; ABREU, 2010). Estes recursos permitem reconhecer os elementos arquiteturais de superfície e subsuperfície através dos padrões de resposta acústica que, por sua vez, auxiliam na interpretação dos agentes erosivo-deposicionais costeiros (COLLINS et al., 1996 apud COOKE et al., 2005).

A estratigrafia sísmica, em seu modo funcional, implica na interpretação de registros sísmicos e análise da estruturação disposta abaixo do assoalho marinho, logo, do arcabouço do subfundo fornecendo uma melhor percepção na identificação de alguns processos oceanográficos e geomorfológicos, sobretudo os processos de grande escala como os oscilatórios do nível do mar. A interpretação sismoestratigráfica faculta ainda a compreensão do arranjo geológico das rochas, das camadas de sedimentos, bem como da evolução e estruturação destes ambientes deposicionais/erosionais. Dessa maneira é possível reconstituir cenários pretéritos e ao mesmo tempo entender a evolução dos ambientes modernos (NEAL et al., 1993; AYRES NETO, 2001).

A análise do cenário a ser investigado tem como base de dados o projeto "Granulados Siliciclásticos da Plataforma Continental Sul-brasileira com Ênfase na Região Adjacente a ilha de Santa Catarina" que foi desenvolvido conjuntamente entre a Universidade do Vale do Itajaí (UNIVALI) e a Universidade Federal de Santa 
Catarina (UFSC), inserido em um estudo mais amplo denominado "Programa de Avaliação da Potencialidade Mineral da Plataforma Continental Jurídica Brasileira (REMPLAC)", a partir do qual resultou a atual pesquisa que tem como objetivo principal investigar o potencial de jazida de areia na plataforma continental interna adjacente à ilha de Santa Catarina, como subsídio para possíveis projetos de recuperação de praias erodidas.

Para alcançar esse objetivo este trabalho descreve as características dos refletores acústicos registrados nos sismogramas os quais estão relacionados processos sedimentares, modernos e pretéritos, contribuindo também com modelos evolutivos e estudos propostos por Kowsmann et al. (1977), Fairbridge \& Curray (1961) apud Corrêa, (1979); Vieira (1981) Suguio (1999; 2003); Masselink \& Hughes (2003), Abreu \& Calliari (2005), Weschenfelder et al. (2008) e Cooper et al. (2018) para a plataforma continental sudoeste e sul do Brasil.

\section{Desenvolvimento}

O levantamento sísmico foi realizado em duas expedições nos anos de 2009 e 2011, ambas a bordo do NOc. Atlântico Sul, de propriedade da Universidade Federal do Rio Grande (FURG).

Para o levantamento geofísico foi utilizado um sistema sísmico Chirp Sub-BottomProfiler and Bathymetric Echo Souder, modelo Bathy 2010Pтм, marca SyQwest, Inc. com quatro transdutores que operam na frequência de $3,5 \mathrm{kHz}$.

A malha de perfilagem sísmica consistiu de 25 perfis perpendiculares às isóbatas com extensões de em média 5,0Km, e 2 perfis paralelos ao longo da face leste da ilha de Santa Catarina posicionados entre as isóbatas de 10 e $50 \mathrm{~m}$ e distanciados cerca de 1,0MN entre si (Figura 01-).

Os sismogramas foram obtidos digitalmente por meio de uma ferramenta computacional conectada ao sistema de perfilagem (Bathy2010 Acquisition) que monitora, ajusta e armazena em tempo real cada linha sondada.

Os perfis sísmicos, em formato *.ODC, foram importados para o software SonarWiz do fabricante Chesapeake Technology Inc. exclusivo para o processamento, visualização e interpretação digital dos dados.

O processamento incluiu a aplicação de ganhos e filtros específicos para extrair ou atenuar ruídos produzidos pela embarcação e das reflexões oriundas da coluna d'água, propiciando maior qualidade na definição dos refletores, logo, uma melhor geometria do traço (GOMES et al., 2011). A velocidade do som foi ajustada 
para $1.650 \mathrm{~m} / \mathrm{s}$ conforme Macedo et al. (2009) e Pires (2014) sugerem para o mapeamento dos refletores acústicos de camadas sedimentares e reduzir as incertezas nas medidas de distâncias verticais.

Para a delineação dos refletores acústicos foram consideradas a amplitude, continuidade lateral, frequência do sinal, morfologia e geometria e disposição das camadas como atributos sísmicos.

Nesta análise foram destacados os refletores que representam os limites, topo e base, das diferentes camadas que se sucedem verticalmente desde o leito oceânico até as mais profundas diferenciadas por meio do caráter de eco característico (COOKE et al., 2005). As medidas verticais de profundidade de soterramento entre os limites foram obtidas por meio do software específico para processamento e análise SonarWiz, possibilitando aferir as espessuras dos pacotes sedimentares, assim como a verificação das medidas morfológicas dos paleocanais mapeados.

O mapeamento dos paleocanais foi inserido em ambiente SIG (Sistema de Informação Geográfica), pela plataforma ArcGIS em sobreposição ao mapa batimétrico para a verificação e validação das interpretações. 
Figura 01- Mapa da malha de perfilagem sísmica constituída de 25 perfis perpendiculares e 2 perfis paralelos à costa ao longo da Plataforma Continental Interna adjacente a ilha de Santa Catarina entre as isóbatas de 10 e 50m, distanciados cerca de 1,0MN entre si.

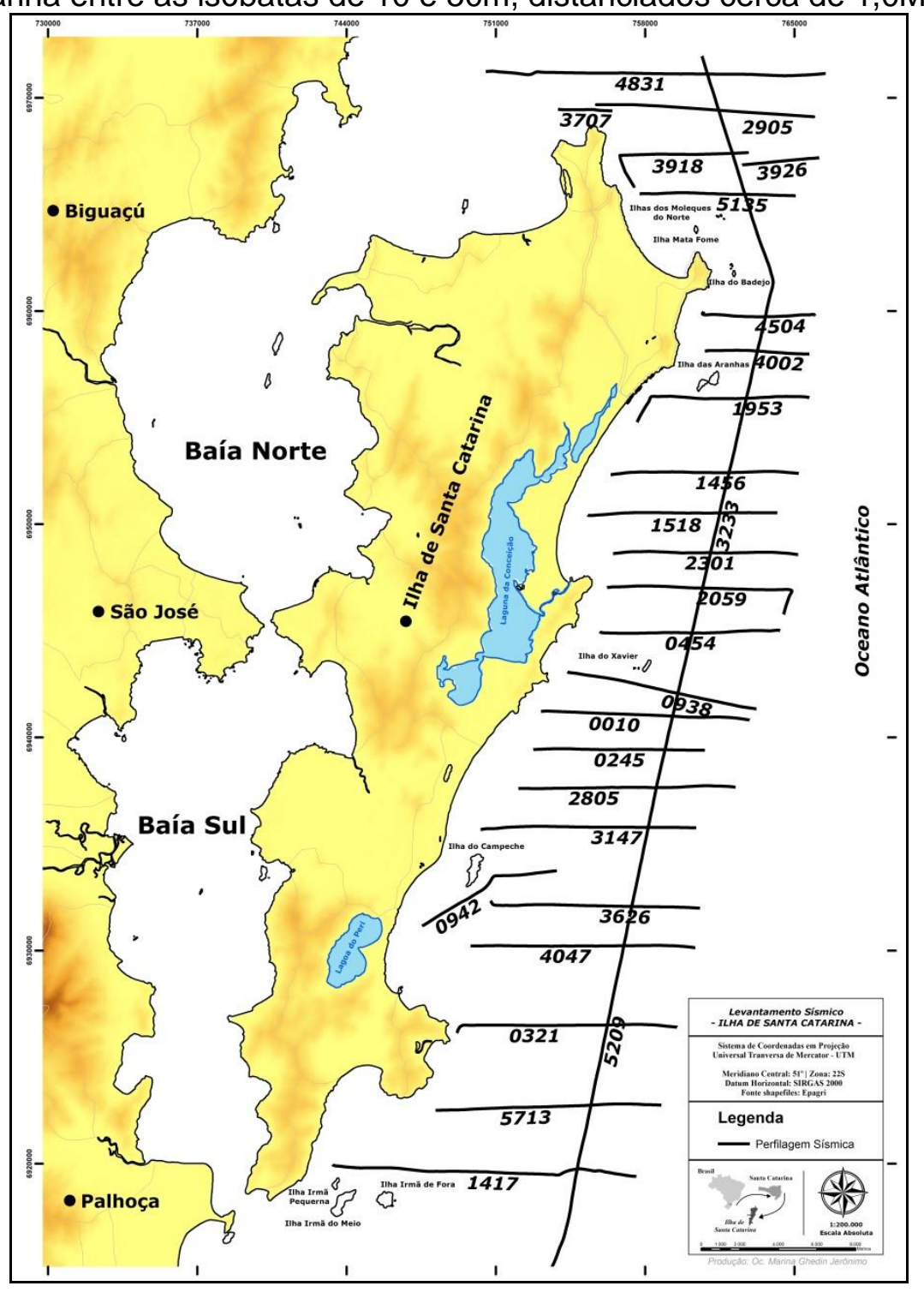

Para a confecção do mapa batimétrico as cotas batimétricas foram extraídas da base cartográfica das Cartas Náuticas (carta 1902) e Folhas de Bordo da Diretoria de Hidrografia e Navegação (DHN), processadas no programa "Sistema de Modelo Costeiro" (SMC - Brasil) e posteriormente interpoladas em ambiente SIG.

Na elaboração dos mapas utilizou-se:

a) Base cartográfica

- Modelo Digital de Elevação - SRTM/NASA-SC. Fonte: Modelo Digital de Elevação SRTM/NASA-SC, ajustado (EPAGRI, 2005).

- Shapefiles dos contornos hidrológicos e das ilhas do Estado de Santa Catarina, extraídos das cartas Biguaçu, Florianópolis, Paulo Lopes, Canasvieiras e Lagoa. Fonte: Mapoteca Topográfica Digital de Santa Catarina. EPAGRI/IBGE (2004). 
Todos os dados foram referenciados ao Sistema de Coordenadas em Projeção Universal Transversa de Mercator - UTM e Datum horizontal: SIRGAS2000.

Dos registros sísmicos interpretados foi possível observar que a penetração acústica atingiu em média 30 a $40 \mathrm{~m}$ de coluna sedimentar cujas reflexões se destacam por uma forte impedância acústica e, de forma geral, continuidades laterais bem definidas.

Os refletores acústicos mapeados, representativo dos contatos entre as camadas deposicionais foram denominados $R 1$, como refletor correspondente ao piso marinho, $R 2$ a paleosuperfície mais rasa e $R 3$ a mais profunda.

A conformação dos horizontes acústicos mapeados mostrou-se de forma variável entre os registros sísmicos interpretados. As reflexões $R 2$ situadas logo abaixo da superfície marinha apresentam um paleorelevo relativamente suave. Em grande maioria comportam-se de forma plano-paralelo em relação ao refletor que corresponde ao leito marinho (R1), entretanto, em outros casos exibem-se de forma mergulhante. Algumas irregularidades deste paleorelevo são observadas próximas às feições acanaladas de menores dimensões. Este horizonte acústico foi identificado entre 0,5 e $8,0 \mathrm{~m}$ de profundidade de soterramento que, pela sua espessura relativamente pequena, pode ser considerado como pertencente a uma sequência transgressiva mais recente.

O terceiro refletor (R3) configura-se de forma irregular, cujas profundidades mínimas e máximas entre o fundo marinho atual e o talweg dos canais soterrados variaram de 12 a $21 \mathrm{~m}$.

Esta reflexão foi identificada em grande parte das linhas sísmicas a partir da isobatimétrica de $20 \mathrm{~m}$, exibindo reflexões internas truncadas e irregulares, indicativas de movimentos de massa submarinos conforme descrevem Ayres Neto et al. (2009).

Oito estruturas sedimentares correlacionadas aos paleocanais foram identificadas nas porções Norte e Centro-Sul da ilha de Santa Catarina em cinco perfis transversais à linha de costa e em um no sentido paralelo à mesma (Figura 02-).

Suas dimensões apresentam medidas que variam de 3 a $20 \mathrm{~m}$ de profundidade no pacote sedimentar sobrejacente e largura variando de 80 a 590m entre as bordas. 
Figura 02- Mapa de localização dos paleocanais (demarcados pelos triângulos) identificados na Plataforma Continental Interna adjacente à ilha de Santa Catarina.

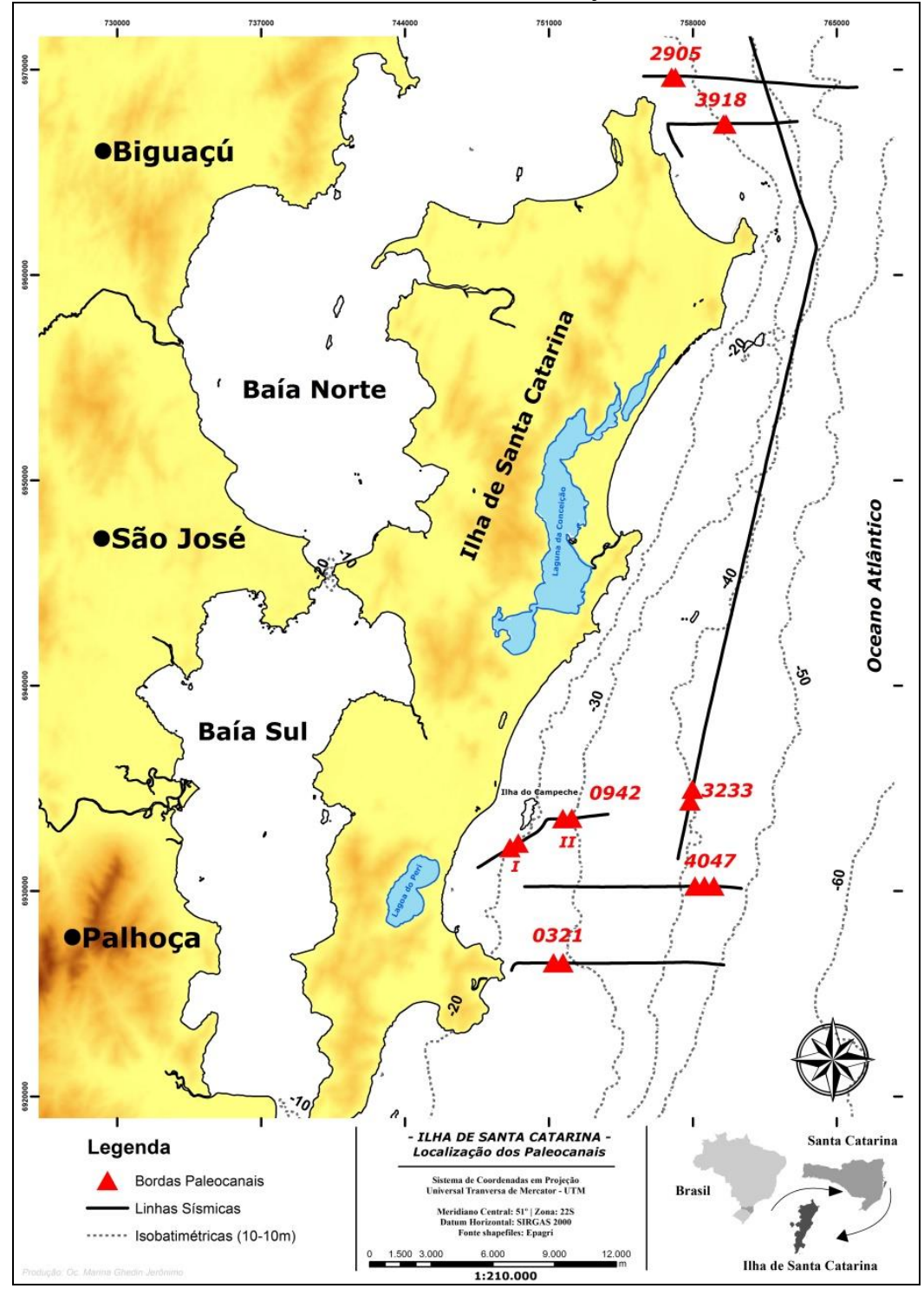

De norte para sul o primeiro paleocanal mapeado situa-se no perfil 2905 (Figura 03-) sob a isóbata de 19m. Apresenta uma forma acanalada com os bordos do canal aflorando na superfície do fundo submarino o que supostamente pode indicar que o soterramento se deu mais recentemente dentro de uma escala tempo geológica. Identificado no refletor acústico $R 2$, a sua profundidade de soterramento relativamente rasa sugere ser o leito de um paleocanal que esteve ativo na Época Holoceno.

É o canal de menor dimensão identificado no presente trabalho, apresentando cerca de $3 \mathrm{~m}$ de profundidade e $8 \mathrm{~m}$ de largura na seção horizontal orientada sentido oeste-leste e reflexões internas indicativas de diferentes estágios deposicionais ausentes. 
Figura 03- A: Linha sísmica 2905 situada na porção norte da Plataforma Continental Interna ao largo da ilha de Santa Catarina. B: Principais refletores identificados. Leito submarino atual $(R 1)$ e estrutura interpretada como paleocanal observado no refletor acústico $R 2$.

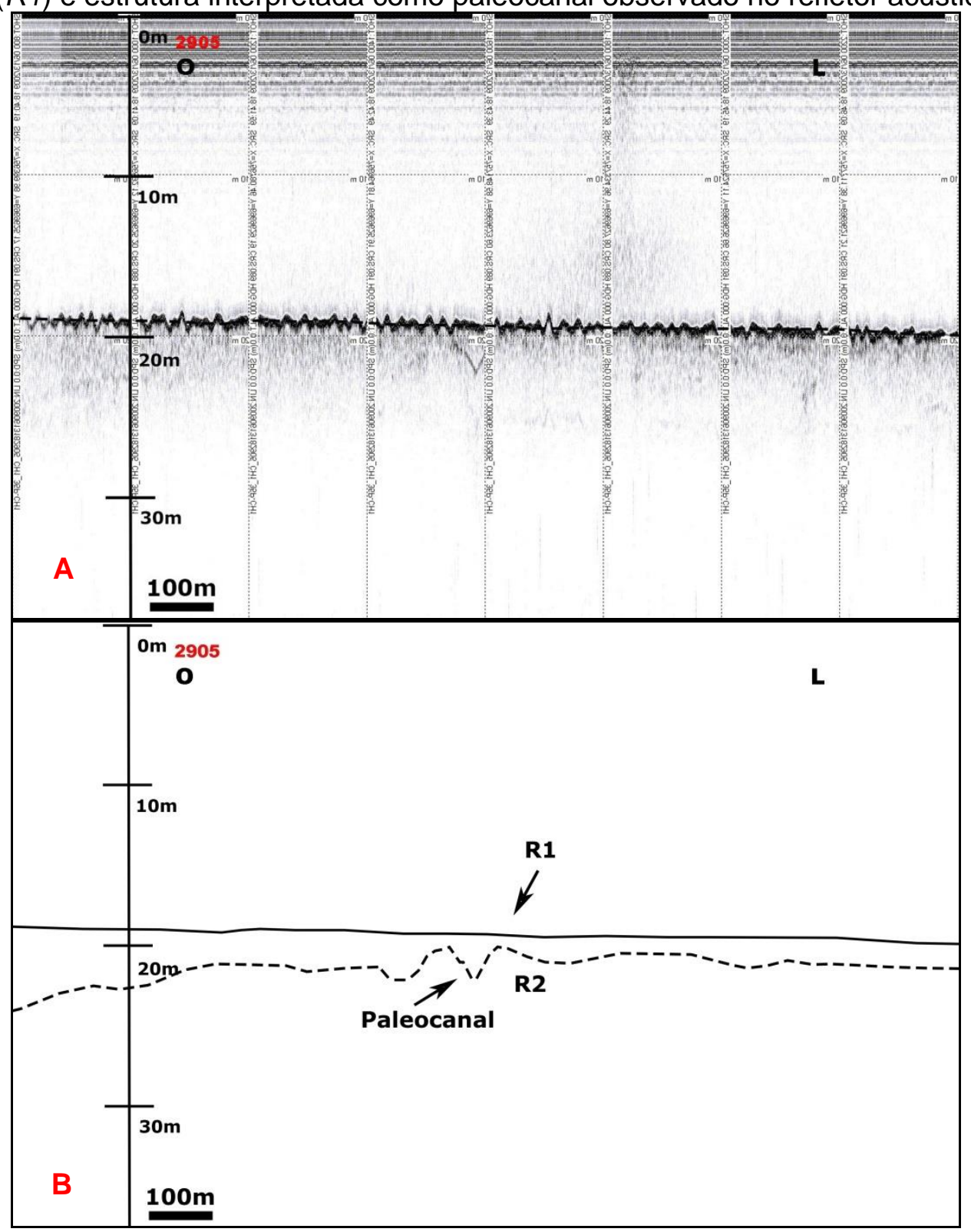

O segundo paleocanal também identificado na porção norte da área sondada (perfil 3918) está localizado na isóbata de $21 \mathrm{~m}$ e apresenta dois refletores distintos em subsuperfície. O primeiro, um horizonte indicativo de uma presumível estabilização do nível do mar, e o segundo exibindo um formato acanalado, inserido completamente dentro de um pacote sedimentar possivelmente pleistocênico, indicando o leito de um canal desta época geológica. A profundidade do canal, considerada a medida vertical entre o talweg e a sua margem é de cerca de $5 \mathrm{~m}$ e a largura da seção horizontal com orientação oeste-leste é de aproximadamente $142 \mathrm{~m}$. 
Figura 04- A: Perfil sísmico 3918 localizado na porção norte da Plataforma Continental Interna ao largo da ilha de Santa Catarina. B: Principais refletores identificados. Leito submarino atual $(R 1)$ e estrutura interpretada como paleocanal observado no refletor

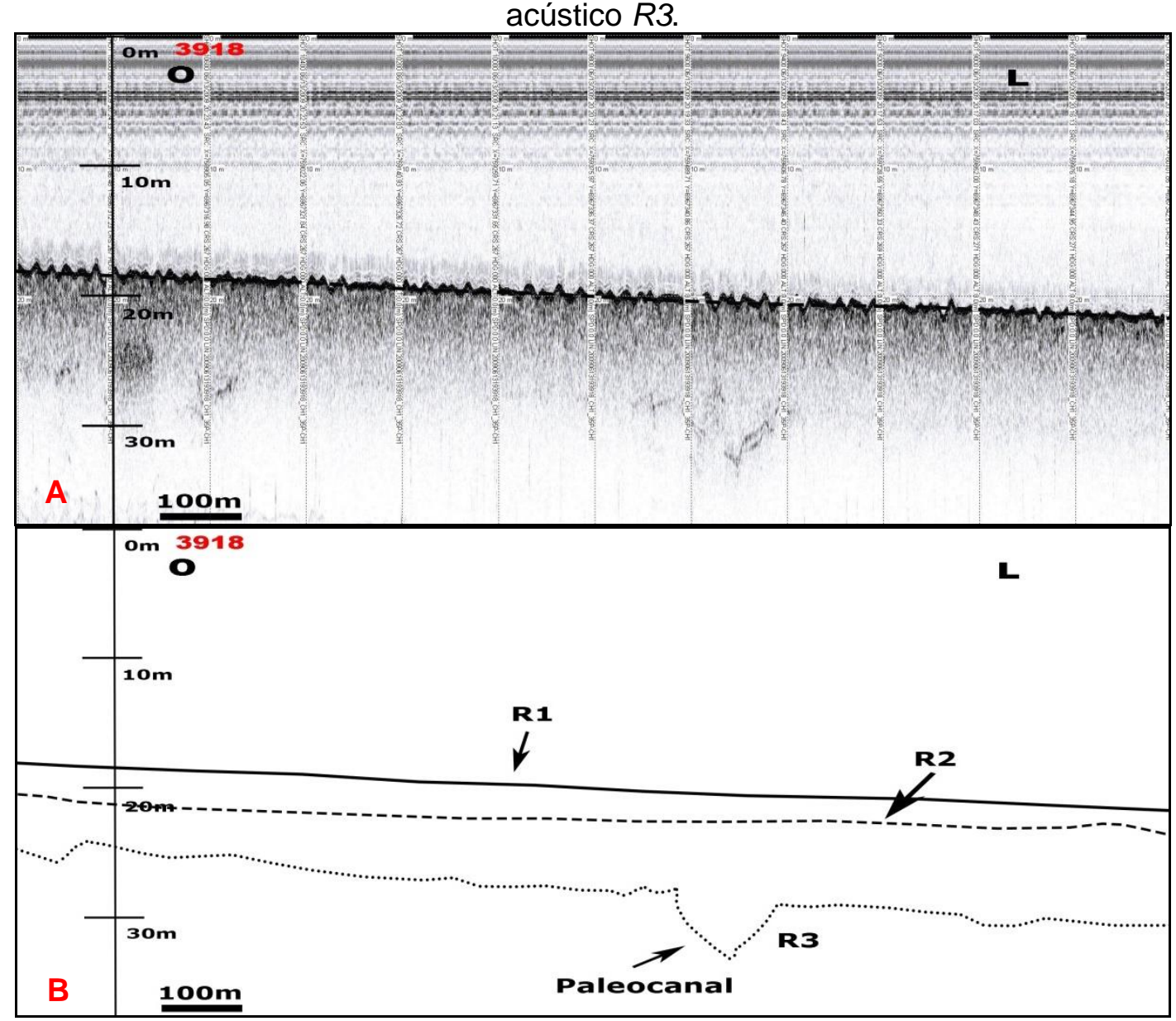

Ao sul da área de estudo foram identificadas seis estruturas soterradas em forma de canal. Dois paleocanais foram identificados no perfil 0942, obtidos no entorno da ilha do Campeche a 20 e $30 \mathrm{~m}$ de profundidade respectivamente, ambos associados ao refletor $R 2$ (Figura 05 - e Figura ). O primeiro, situado mais próximo da costa exibe uma forma mais aplainada com profundidade de 3,5m e largura de $131 \mathrm{~m}$. Sua seção transversal orienta-se de sudoeste para nordeste onde as margens tendem a aflorar em superfície. Já o segundo possui orientação oeste-leste com largura entre as bordas de $103 \mathrm{~m}$ e profundidade de soterramento de em média $6 \mathrm{~m}$. Embora estes configurem-se distintamente quanto à topografia do leito, possivelmente encontravam-se ativos no mesmo período geológico. Estes dois paleocanais, considerando a proximidade entre eles e a mudança da orientação da seção transversal, são muito provavelmente pertencentes ao mesmo canal fluvial que meandrava pela antiga planície costeira emersa durante um episódio regressivo. 
Figura 05 - A: Perfil sísmico 0942 obtido na porção centro-sul da Plataforma Continental Interna ao largo da ilha de Santa Catarina. B: Principais refletores identificados. Leito submarino atual $(R 1)$ e estrutura interpretada como paleocanal observado no refletor

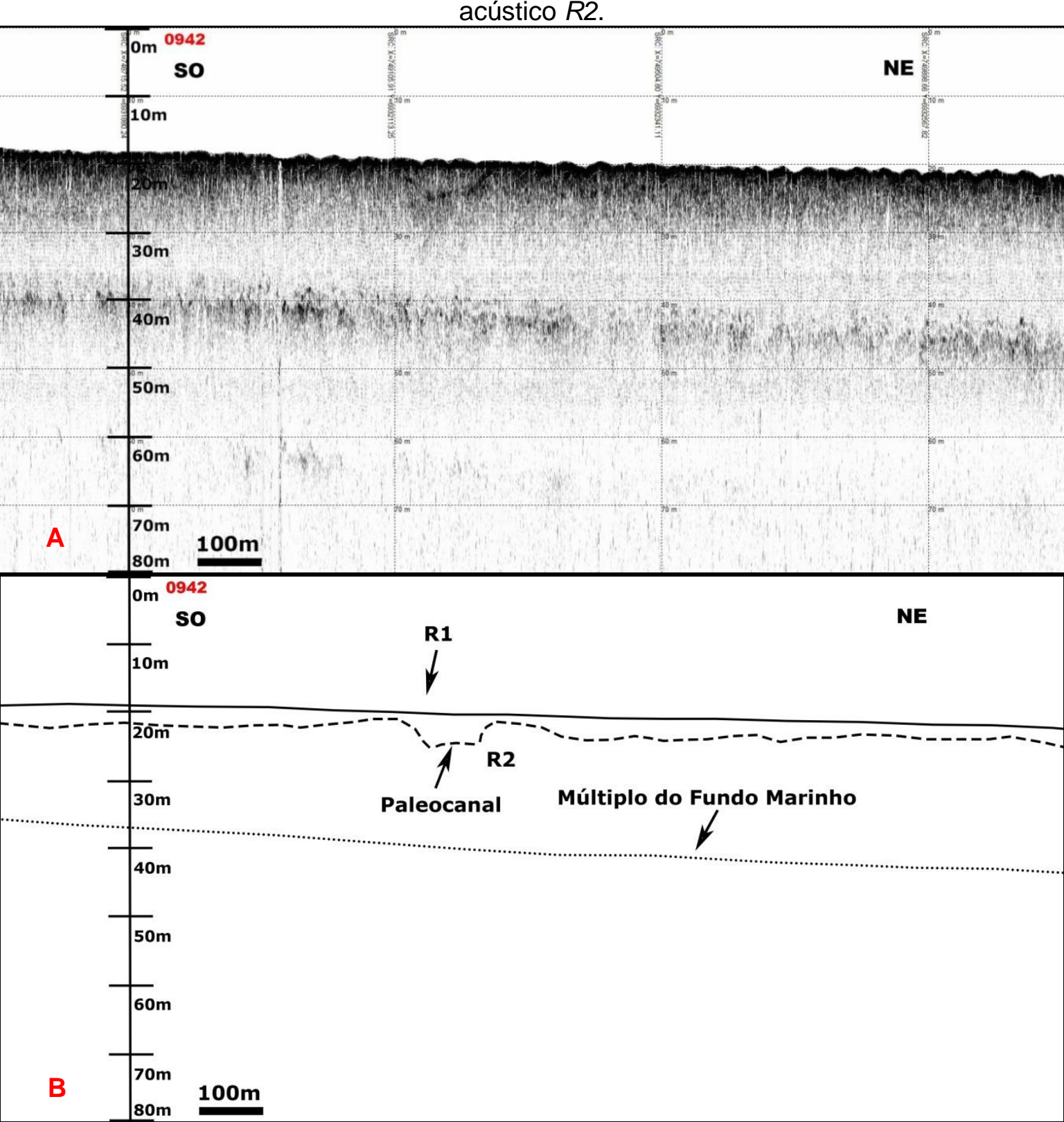


Figura 06 - A: Perfil sísmico 0942 localizado na porção sul da Plataforma Continental Interna ao largo da ilha de Santa Catarina B: Principais refletores identificados. Leito submarino atual $(R 1)$ e estrutura interpretada como paleocanal observado no refletor

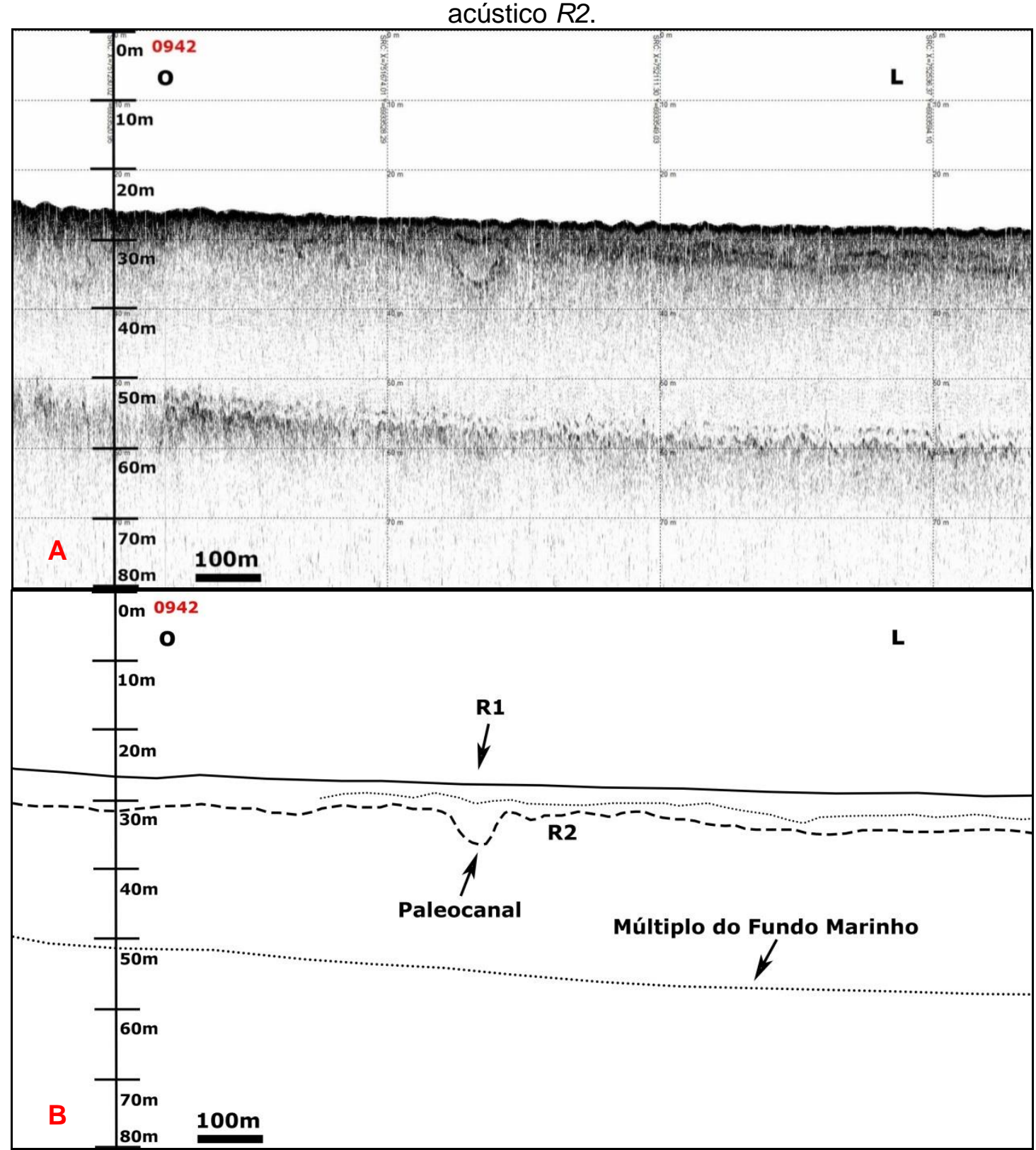

Com características semelhantes, outros dois paleocanais foram mapeados no perfil 4047 (Figura 07). Estes são pertencentes ao horizonte acústico $R 3$, a cerca de $55 \mathrm{~m}$ de profundidade, apresentam continuidades laterais bem definidas e, sobretudo, reflexões internas ao pacote sedimentar que, presumivelmente, indicam episódios de soterramento. 
Figura 07-. A: Perfil sísmico 4047 obtido na porção centro-sul da Plataforma Continental Interna ao largo da ilha de Santa Catarina. B: Principais refletores identificados. Leito submarino atual $(R 1)$ e estruturas interpretadas como paleocanais observados no refletor

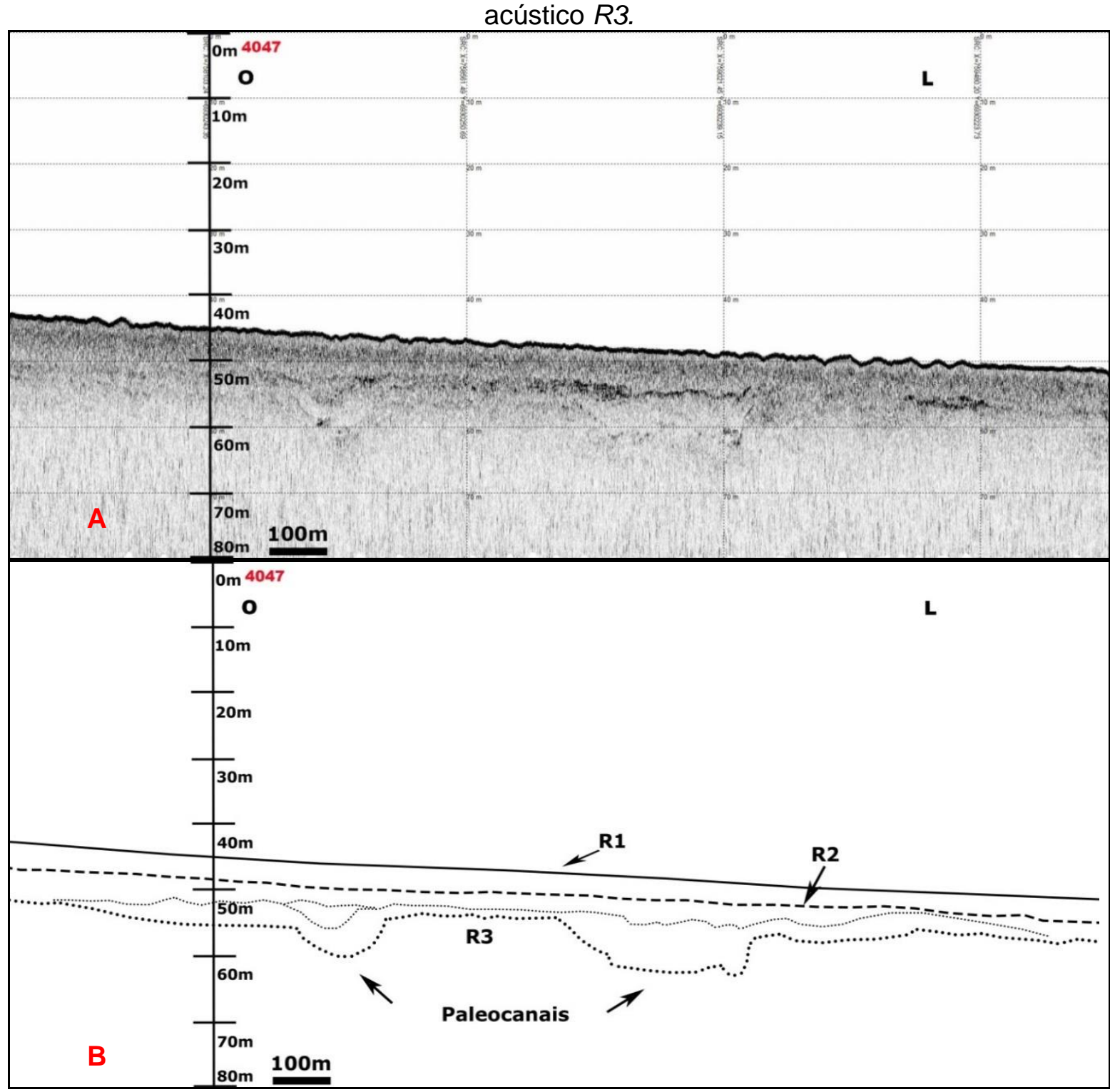

Dispostos entre as isóbatas de 45 e $47 \mathrm{~m}$ têm aproximadamente $100 \mathrm{~m}$ de largura, distanciam-se cerca de $460 \mathrm{~m}$ e estão soterrados entre 6 e 7m de profundidade.

De forma idêntica ao descrito para os paleocanais registrados no perfil 0942 (Figura 6), estes dois paleocanais são também pertencentes ao mesmo sistema de drenagem, porém, por situarem-se a uma profundidade maior, são mais antigos e devem se relacionar a um período regressivo anterior. Estabelecidos por completo dentro de um pacote sedimentar mais profundo, estão relacionados a uma sequência sedimentar provavelmente pleistocênica. No mesmo perfil, o refletor $R 2$, mais raso, apresenta paleosuperfície em conformidades plano-paralelas com $R 1$ as quais demarcam claramente o limite entre os dois pacotes sedimentares. 
O mesmo padrão de reflexões foi averiguado nos perfis 0321 (Figura) e 3233 (Figura). Com eco-caráter similar e presente em toda a área investigada, o horizonte acústico R3 se destaca por apresentar estruturas de corte e preenchimento (paleocanais), truncamentos e posição inferior na estratigrafia sísmica desta parte da plataforma, sendo as reflexões superiores indicativas de estágios posteriores de deposição.

Posicionado sob a isóbata de $30 \mathrm{~m}$, o paleocanal mapeado no perfil 0321 está à profundidade média de soterramento de $10 \mathrm{~m}$, largura de $276 \mathrm{~m}$ e apresentando estruturas deposicionais de preenchimento bem visíveis no seu interior.

A continuidade lateral das reflexões sobrejacentes que, por conseguinte, pertencem a pacotes sedimentares mais recentes são correspondentes à atual topografia do fundo submarino. Estas apresentaram espessuras de 3 à $5 \mathrm{~m}$ o que caracteriza uma relativa homogeneidade nos processos deposicionais durante os estágios finais da construção da plataforma continental. 
Figura 08- A: Perfil sísmico 0321 obtido na porção centro-sul da Plataforma Continental Interna ao largo da ilha de Santa Catarina. B: Principais refletores identificados. Leito submarino atual $(R 1)$ e estrutura interpretada como paleocanal observado no refletor

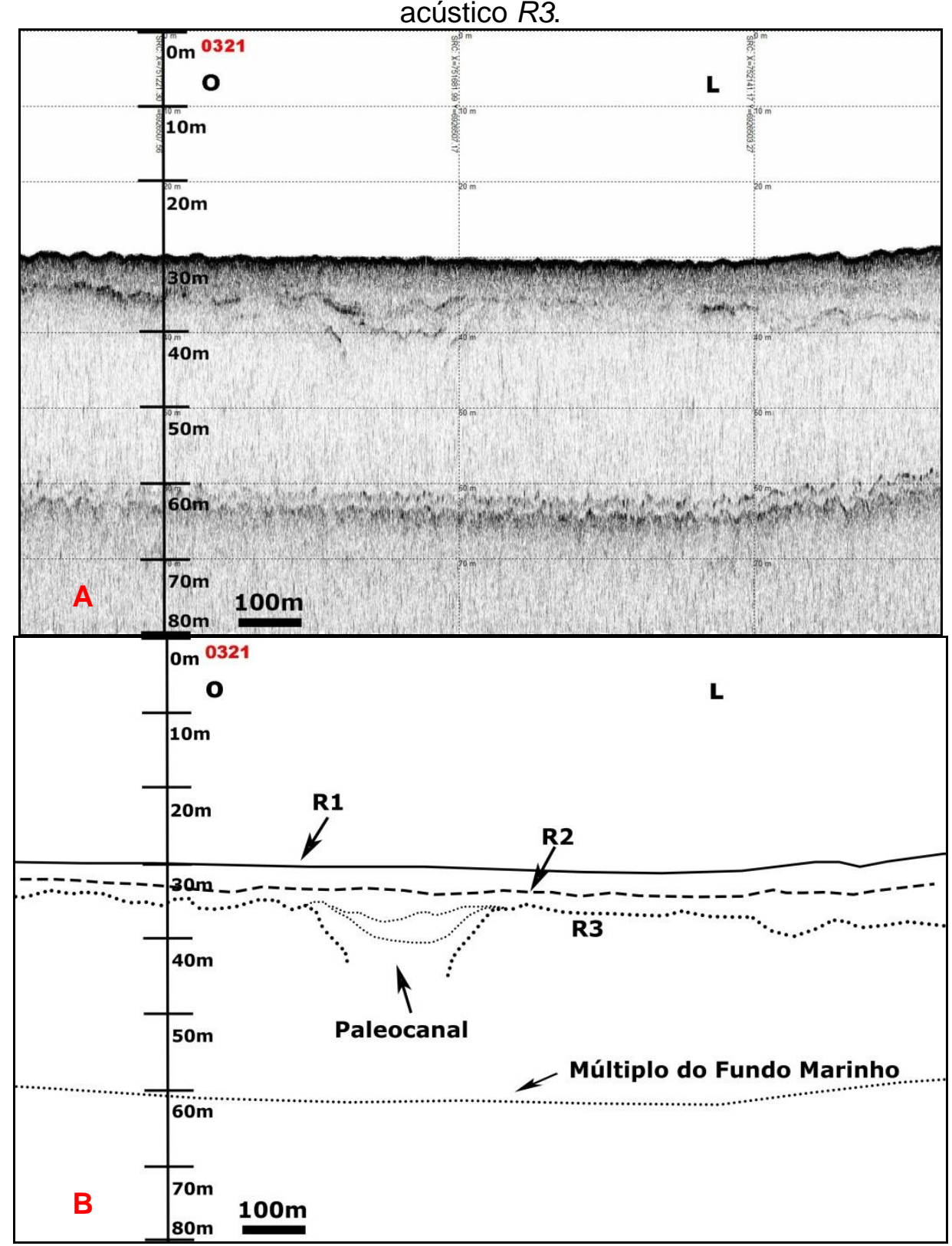

Tal estrutura deposicional também é registrada entre as reflexões $R 3$ e $R 2$ no perfil 3233. Pertencente à linha sísmica perfilada longitudinalmente à costa, o paleocanal mapeado possui as maiores dimensões de profundidade e largura dentre os identificados em toda a área mapeada. Com média de $11 \mathrm{~m}$ de profundidade de soterramento até o talweg e $590 \mathrm{~m}$ de largura, a seção transversal desta paleosuperfície orienta-se nos sentidos sul-norte e posiciona-se sob a isolinha de $40 \mathrm{~m}$. Embora apresente a maior largura entre todos os paleocanais identificados a linha sísmica provavelmente percorreu longitudinalmente um trecho deste canal. 
Figura 09 - A: Perfil sísmico 3233 obtido na porção centro-sul da Plataforma Continental Interna ao largo da ilha de Santa Catarina. B: Principais refletores identificados. Leito submarino atual $(R 1)$ e estrutura interpretada como paleocanal observado no refletor acústico $R 3$.

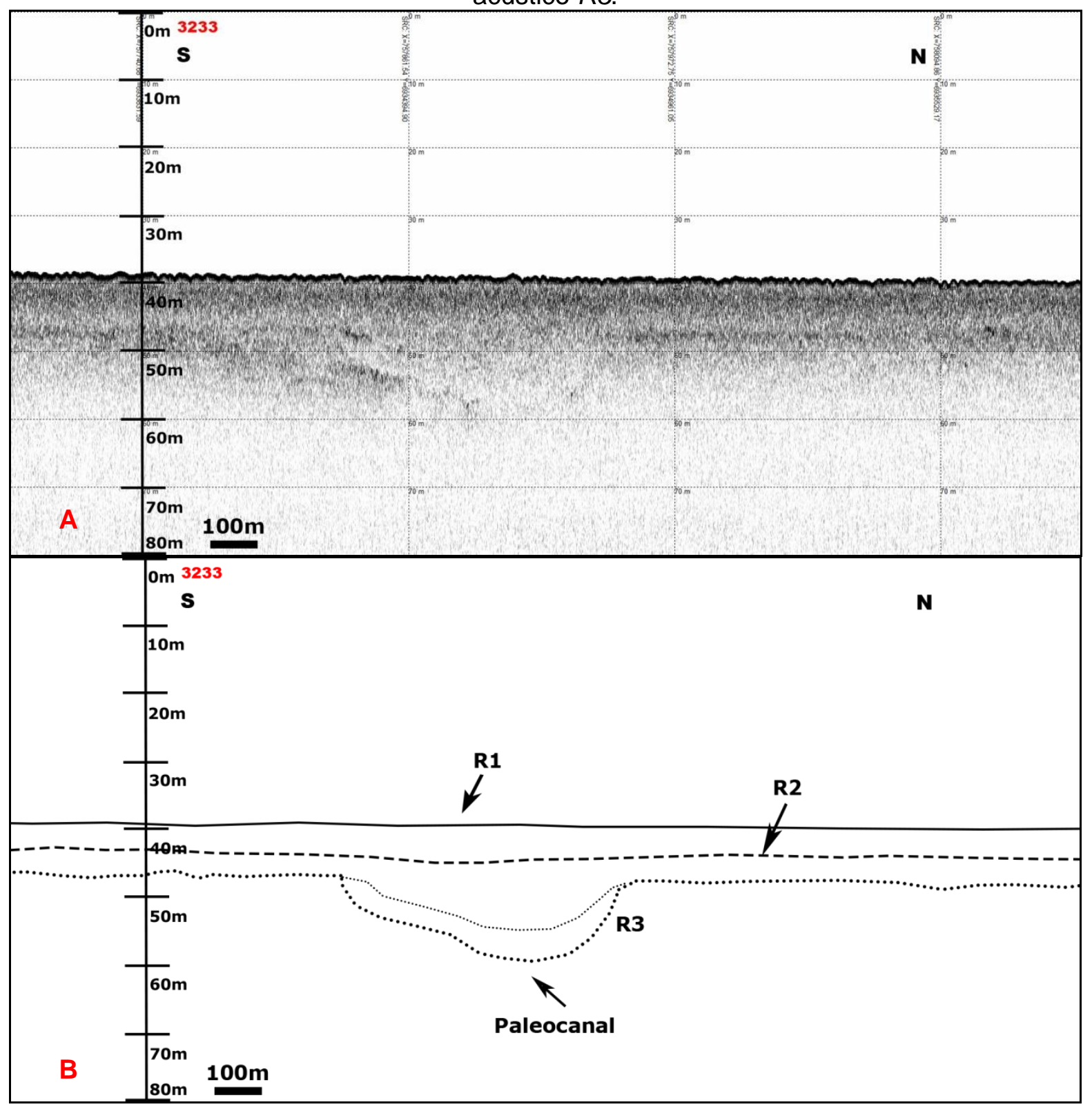

A interpretação dos perfis sísmicos realizada neste trabalho permitiu identificar dois horizontes acústicos os quais representam os limites superiores e inferiores (topo e base) entre duas sequências sedimentares que compõem a arquitetura da plataforma continental interna ao largo da ilha de Santa Catarina.

A primeira sequência delimitada, entre o leito marinho $(R 1)$ e o primeiro horizonte acústico mapeado $(R 2)$, tem um relevo suave e espessuras mínimas e máximas de 10 e 12m, respectivamente. Para a sequência situada mais abaixo, delimitada pelos refletores $R 2$ (topo) e $R 3$ (base), foram obtidas medidas de espessura entre 14 e $32 \mathrm{~m}$, a qual apresenta morfologia irregular típica de ambientes 
que se destacam por processos de transporte e deposição sedimentar mais intensificados.

Tais horizontes acústicos foram correlacionados a distintos estágios de altura do nível do mar atingidos pelas oscilações eustáticas que marcaram o Período Quaternário e que foram fundamentais para a construção e configuração interna da moderna plataforma continental.

Neste sentido, o horizonte acústico mais profundo $(R 3)$ demarca a base de uma sequência sismo-estratigráfica, provavelmente durante a Época Pleistoceno (1,8Ma AP - 0,01Ma AP), construída durante um ciclo regressivo do nível do mar, em cenário de planície costeira progradante. Evidencias desta regressão marinha e da existência deste extensa planície costeira posteriormente afogada e retrabalhada pelo nível do mar transgressivo que sucedeu o ultimo período glacial foram apresentadas por Kowsmann et al. (1977). O autor descreveu testemunhos coletados durante o Cruzeiro REMAC - Águas Rasas (1974) ao sul da ilha de Santa Catarina numa profundidade de $136 \mathrm{~m}$ e datados por ${ }^{14} \mathrm{C}$, foram relacionados a uma linha de costa pretérita de cerca de 30mil anos AP, época também associada ao Último Máximo Glacial.

Já a paleosuperfície mais rasa $(R 2)$ representa a base de uma sequência sedimentar transgressiva, possivelmente holocênica, a qual soterrou e preencheu canais da drenagem fluvial e outras estruturas erosivas construídas no período geológico anterior.

Estruturas sedimentares presentes internamente ao prisma sedimentar são as evidências destes antigos sistemas de drenagem que se encontram atualmente soterrados por uma unidade sedimentar mais recente. Esses elementos arquiteturais denominados de paleocanais, paleodrenagens e/ou paleovales, sugerem a presença de uma rede de drenagem fluvial pretérita que se encontrava ativa e posteriormente soterrada em consequência de eventos eustáticos ocorridos durante o Período Quaternário.

A interpretação dos registros possibilitou ainda uma hierarquia de redes de drenagem. Paleocanais foram identificados na sequencia sísmica superior (R1-R2), mais recentes, que podem ter se desenvolvido durante estágios estacionários do ciclo transgressivo holocênico (CORRÊA et al., 1996; FURTADO, 2013). Outros paleocanais localizados na unidade sísmica inferior $(R 2-R 3)$ são de idade pleistocênica compondo estes uma rede mais antiga. 
Sistemas de paleodrenagens semelhantes foram descritos por Abreu \& Calliari (2005) na plataforma continental interna no Rio Grande do Sul, mapeados através de levantamento sísmico de alta resolução e concomitante análise de amostras superficiais dos sedimentos.

A utilização da sísmica de alta resolução, apoiada pelo mapeamento geológico, constatou que nas porções da plataforma média uma cobertura superficial de sedimentos lamosos sobre as fácies areno-quartzosas que acabam por aflorar na plataforma interna, resultantes do retrabalhamento do substrato pleistocênico, o que permitiu caracterizar o corpo lamoso como material depositado durante o último ciclo transgressivo.

Além disso, a existência de escarpas no substrato arenoso foi observada nas isóbatas de 60 e $110 \mathrm{~m}$, representativas de antigas linhas de costa desenvolvidas com rápidos estágios de estabilização no decorrer da transgressão Santos (KOWSMANN et al., 1977).

Neste particular, os refletores acústicos identificados neste trabalho delimitam antigos cenários deposicionais, evidenciando antigos sistemas de drenagem fluviais que se estendiam sobre uma antiga planície costeira em períodos de nível eustático regressivo.

\section{Considerações Finais}

A disposição dos refletores acústicos, em toda a área sondada, se apresentou de forma variável ao longo de todos os perfis sísmicos interpretados, especialmente entre o horizonte acústico correspondente ao fundo marinho $(R 1)$ e o seguinte, mais profundo (R2). Comportando-se ora de forma mergulhante, ora acompanhando paralelamente o refletor sobrejacente, indicando ser uma região submetida aos processos geológicos mais recentes, de transporte e sedimentação, decorrentes das oscilações no nível médio do mar nos diferentes estágios de estabilização que se alternam desde 6.000Ma AP aos dias atuais, onde o nível do mar alcançou seu máximo e a amplitude das oscilações diminuiu (VIEIRA, 1981).

A reflexão subjacente $R 3$ foi visualizada de forma descontínua e/ou truncada em grande parte dos registros e suas superfícies dispuseram-se levemente irregulares, exibindo algumas regiões com relevo mais escarpado e de nivelamento variável, indicativo de processos deposicionais/erosicionais de alta magnitude, presumivelmente de idade pleistocênica. 
No que tange à presença de paleocanais ao norte e centro-sul na plataforma interna, as conclusões apontam para a identificação de uma drenagem pretérita cujas estruturas mapeadas no setor norte, sugerem ser o antigo leito do rio Biguaçu, e, em relação aos localizados na porção centro-sul da ilha de Santa Catarina, podem estar relacionados a uma antiga conexão (in let) da moderna Lagoa do Peri, onde ambos se estendiam por meio da planície costeira num período de mar regressivo em que a atual ilha de Santa Catarina estava anexada a terrenos continentais. Neste período de tempo (Época Holoceno) há aproximadamente de 11.000 AP., o nível relativo do mar encontrava-se nas atuais isóbatas de $20 / 25 \mathrm{~m}$ e $32 / 45 \mathrm{~m}$, numa ascensão que terminou por soterrar os canais fluviais até então existentes com sedimentos marinhos transgressivos (CORRÊA, 1979).

As mencionadas estruturas acanaladas posicionadas sobre o horizonte acústico R3, assim como similaridades nas medidas de largura quando analisadas em seções de diferentes sentidos (Leste-Oeste, Nordeste-Sudoeste e Norte-Sul) e o aumento da distância entre as bordas à medida em maiores profundidades, dão sustentação à hipótese de um possível comportamento meandrante apresentado por essa antiga rede de drenagem fluvial.

Desta forma, os processos evolutivos que levaram à configuração dos últimos depósitos sedimentares superficiais e subsuperficiais rasos presentes da plataforma continental interna adjacente à Ilha de Santa Catarina evidenciaram um forte condicionamento das flutuações do nível do mar que ocorreram entre o Pleistoceno Superior e o Holoceno, desde 30.000 anos AP até o presente.

Sobretudo, associados à fase transgressiva iniciada após o último Máximo Glacial, há aproximadamente 18.000 anos AP, resultando no afogamento de desembocaduras fluviais, da planície costeira pretérita e posterior recobrimento por um "lençol de areias transgressivas" nos estágios intermediários da Época Holoceno.

\section{REFERÊNCIAS}

ABREU, J.G.N. Sedimentologia, sismoestratigrafia e evolução da Plataforma Continental Interna na área sob influência dos rios Itajaí-Açu e Camboriú, litoral centro-norte de Santa Catarina. 2010. Tese (Doutorado em Ciências) - Programa de PósGraduação em Geociências, Universidade Federal do Rio Grande do Sul, Porto Alegre. 2010. 
ABREU, J.G.N. e CALLIARI, L.J. Paleocanais na Plataforma Continental Interna do Rio Grande do Sul: Evidencias de uma Drenagem Fluvial Pretérita. Revista Brasileira de Geofísica, Rio de Janeiro, v. 23, n. 2, p. 123-132, out. 2005.

AYRES NETO, A. Uso da sísmica de reflexão de alta resolução e da sonografia na exploração mineral submarina. Revista Brasileira de Geofísica, Rio de Janeiro, v. 18, n. 3, p. 241-256, dez. 2001.

AYRES NETO, A.; FALCÃO, L.C. e AMARAL, P.J.T. Caracterização de ecofácies na margem continental norte brasileira - Estado do conhecimento. Revista Brasileira de Geofísica, Rio de Janeiro, v. 27, n. 1, p. 97-106, 2009.

COOKE, C.V.; MADUREIRA, L.S.P. e GRIEP, G.H. Análise de dados batimétricos provenientes de cruzeiros de prospecção de recursos vivos realizados entre Fortaleza (CE) e Florianópolis (SC). In: CONGRESSO BRASILEIRO DE P\&D EM PETRÓLEO E GÁS, 3., 2005, Bahia. Resumos [...]. Salvador: Instituto Brasileiro de Petróleo e Gás (IBP) e UNIFACS, 2005.

CORRÊA, I.C.S. Paleolinhas de costa na plataforma continental entre São Paulo e Santa Catarina. In: SIMPÓSIO REGIONAL DE GEOLOGIA, 2., 1979, Rio Claro. Atas [...]. São Paulo, 1979.

CORRÊA, I.C.S.; MARTINS, L.R.S.; KETZER, J.M.M.; ELIAS, A.R.D.; MARTINS, R. Evolução Sedimentológica e Paleogeográfica da Plataforma Continental Sul e Sudeste do Brasil. Notas Técnicas, 9: 51-61. CECO. Instituto de Geociências. UFRGS. Porto Alegre. Brasil. 1996.

COOPER, J.A.G.; MEIRELES, R.P.; GREEN, A.N.; KLEIN, A.H.F. e TOLDO, E.E. Late Quaternary stratigraphic evolution of the inner continental shelf in response to sea-level change, Santa Catarina, Brazil. Marine Geology. v. 397, p. 1-14. 2018.

GOMES, M.P.; VITAL, H. e MACEDO, J.W.P.de. Fluxo de Processamento Aplicado a dados de Sísmica de Alta Resolução em Ambiente de Plataforma Continental. Exemplo: MacauRN. Revista Brasileira de Geofísica, Rio de Janeiro, v. 29, n. 1, p. 173-186. 2011.

FURTADO, V.V. Upper quaternary sea level fluctuations and stillstands on the continental shelf of São Paulo State, Brazil: A Summary. Revista Brasileira de Geofísica, Rio de Janeiro, v.31, Supl.1, p.43-48. 2013.

KOWSMANN, R.O.; COSTA, M.P.A.; VICALVI, M.A.; COUTINHO, M.G.M. e GAMBÔA, L.A.P. Modelo da sedimentação holocênica na plataforma continental sul brasileira. In Projeto REMAC - Evolução sedimentar holocênica da plataforma continental e do talude do Sul do Brasil. Série Projeto REMAC, 2: 7-26. Rio de Janeiro, PETROBRAS, CENPES, DINTEP. 1977.

MACEDO, H.C.; FIGUEIREDO Jr., A.G. e MACHADO, J.C. Propriedades acústicas (velocidade de propagação e coeficiente de atenuação) de sedimentos marinhos coletados nas proximidades da llha do Cabo Frio, RJ. Revista Brasileira de Geofísica, Rio de Janeiro, v. 27, n. 2, p. 195-204, jun. 2009.

MASSELINK, G. e HUGHES, M.G. Introduction to coastal processes and geomorphology. Hodder Education Publishers, London, UK. 2003.

NEAL, J.; RISCH, D. e VAIL, P. Sequence Stratigraphy - A Global Theory for Local Success. Oilfield Review, Chester, v. 5, p.51-63. 1993. 
PIRES, J. C. G. Análise do desempenho da Ultrassonografia no Imageamento não invasivo de Depósitos Sedimentares simulados em Laboratório. 2014. Dissertação (Mestrado em Engenharia e Tecnologia de Materiais) - Universidade Católica do Rio Grande do Sul, Porto Alegre. 2014.

SUGUIO, K. Recent progress in Quaternary geology of Brazil. Episodes, São Paulo, v. 22, n. 3, p, 217-220, set. 1999.

SUGUIO, K. Geologia Sedimentar. 1 ed. São Paulo: Edgard Blucher, 2003.

SUMIDA, P.Y.G.; YOSHINAGA, M.Y.; MADUREIRA, L.A.S. e HOVLANND, M. Seabed pockmarks associated with deepwater corals off SE. Brazilian continental slope, Santos Basin. Marine Geology, v. 207, p.159-167, jun. 2004.

VIEIRA, P.C. 1981. Variações no nível marinho: Alterações eustáticas do Quaternário. Revista IG, São Paulo, v. 2, n. 1, p.39-58, jun. 1981.

WESCHENFELDER, J.; CORRÊA, I.C.S.; TOLDO Jr, E.E. e BAITELLI, R. Paleocanais como indicativo de eventos regressivos Quaternários do nível do mar no sul do Brasil. Revista Brasileira de Geofísica, Rio de Janeiro, v. 26, n. 3, p. 367-375, abr. 2008.

\section{NOTAS DE AUTOR}

\section{CONTRIBUIÇÃO DE AUTORIA}

Marina Ghedin Jerônimo - Concepção e elaboração do manuscrito. Coleta, processamento e análise de dados. Discussão dos resultados; Revisão e aprovação da versão final do trabalho.

José Gustavo Natorf de Abreu - Discussão dos resultados; Revisão e aprovação da versão final do trabalho.

FINANCIAMENTO

Não se aplica.

CONSENTIMENTO DE USO DE IMAGEM

Não se aplica.

APROVAÇÃO DE COMITÊ DE ÉTICA EM PESQUISA

Não se aplica.

CONFLITO DE INTERESSES

Não se aplica.

LICENÇA DE USO

Este artigo está licenciado sob a Licença Creative Commons CC-BY. Com essa licença você pode compartilhar, adaptar, criar para qualquer fim, desde que atribua a autoria da obra.

\section{HISTÓRICO}

Recebido em: 16-12-2019

Aprovado em: 01-06-2020 